\title{
Social Media Marketing Adoption Strategies: An Exploratory Multiple Case Study of Landscape Industry Small Businesses
}

\author{
Crystal Lupo, $\mathrm{PhD}$, DBA
}

American Public University, Charles Town, West Virginia, United States

(iD https://orcid.org/0000-0002-3867-4065

Jason R. Stroman, $\mathrm{PhD}$

University of Phoenix, Phoenix, Arizona, United States

(iD https://orcid.org/0000-0002-4124-762X

Contact: lupo.crystal@gmail.com

\begin{abstract}
Despite research contending that marketing is a pivotal factor in small business success, many small business owners continue to underutilize low-cost marketing options available to them. Of these options, social media marketing is a useful tool to maintain competitiveness in the larger marketplace. However, the adoption of social media best practices in small business remains deficient. The landscape industry is a large and growing field with small businesses making up a large and growing share of the industry. Yet some landscape industry small business owners lack strategies to adopt innovative social media marketing strategies to help ensure business viability. This study incorporated a qualitative, exploratory multiple-case study design to explore how landscape industry small business owners use social media marketing strategies to help ensure business viability. Results indicated that successful marketing strategies tended to incorporate Facebook as the primary social media tool and included content such as service, education, and holiday posts. Benefits of social media marketing primarily centered on low-cost marketing options for improved visibility, while challenges included a trial-and-error learning curve. Results of this study might help small businesses improve their long-term viability through social media marketing strategies.
\end{abstract}

Keywords: social media; marketing; adoption; social exchange; social media marketing; small business; landscape industry

Date Submitted: February 6, 2020 | Date Published: September 17, 2020

\section{Recommended Citation}

Lupo, C., \& Stroman, J. R. (2020). Social media marketing adoption strategies: An exploratory multiple case study of landscape industry small businesses. Journal of Social, Behavioral, and Health Sciences, 14, 211-220. https://doi.org/10.5590/JSBHS.2020.14.1.15

\section{Introduction}

Across the United States, small businesses fail at an alarming rate. Recent research studies have indicated that as many as $54 \%$ of small businesses fail within the first 5 years of operation (Atanassova \& Clark, 2015; Perry, 
Lupo \& Stroman, 2020

2014; SBA, 2016). Several studies point to marketing as a pivotal factor in small business success (Atanassova \& Clark; Gray \& Mabey, 2005; Perry). Despite evidence suggesting that social media marketing is beneficial to small business success and can allow small businesses to remain competitive in the larger marketplace, many small business owners continue to underutilize this low-cost marketing option (Castronovo \& Huang, 2012; Perry; Shang, 2014; Taneja \& Toombs, 2004).

Atanassova and Clark (2015) noted that as small businesses become immersed in social media marketing, they become stronger market contenders by acquiring valuable market intelligence. Incorporating social media best practices within small businesses can help them increase viability and improve competitiveness in the larger marketplace (Broekemeir et al., 2015).

The landscape industry is continually expanding, with revenues averaging 93 billion dollars, and forecasted to grow by $5-6 \%$ annually (IBISWorld, 2018). Successful small businesses within the landscape industry employ, on average, 15 people and have approximately 1.1 million dollars in revenue (IBISWorld). The average profits of successful small landscape companies average around 11\% (Lawn \& Landscape, 2018). Since small landscape businesses make up a large and growing share of the landscape industry, an opportunity exists to increase both revenue and overall vitality with the use of proper social media strategies. This study addresses the specific business problem of some landscape industry small business owners lacking strategies to adopt innovative social media marketing strategies to help ensure business viability. Little to no research currently exists in understanding social media marketing strategies in successful landscape industry small businesses. Thus, the purpose of this qualitative, multiple-case study was to explore how four landscape industry small businesses in central Alabama have successfully incorporated social media marketing strategies to help ensure business viability.

\section{Theoretical Basis}

Adoption theory has previously been used to understand the successful implementation process of a multitude of innovations and new business ideas (Chien-Wen, et al., 2014; Lupo, 2015; Ramirez, 2013; Rogers, 2003; Setiowati, et al., 2001; Taylor, et al., 2011). Elements of adoption theory include an understanding of how innovations begin, communication channels that guide innovations, adoption rates, and adopter categories (Lupo, 2015; Rogers). Rates of adoption vary based on relative advantage, complexity, observability, and compatibility (Rogers). Adoption theory research has focused on identifying specific variables that describe innovation adopters, categorizing adopter variables, and defining socioeconomic differences in adopter groups (Chien-Wen et al.; Lupo, 2015; Ramirez; Rogers; Setiowati et al., 2015; Stone, 2016). Adoption theory is useful for understanding innovations that are new and for understanding the initial incorporation of existing innovations (Lupo, 2015; Rogers). Social media marketing is an existing practice but is considered an innovation due to its underutilization or complete lack of adoption within many landscape industry small businesses (Lupo, 2018).

Once small businesses adopt social media marketing strategies, a series of exchanges occur between the business and customers (De Clercq, et al., 2010). All economic actions between the business and customers become a balance between business self-interest and the development of sustainable relationships (De Clercq, et al.). Social exchange theory has the potential to maximize mutual benefits while minimizing costs (Homans, 1958; Surma, 2016). In this sense, social exchange theory was used to understand how social behavior resulted from this exchange process.

Online social networks, like Facebook or Twitter, are an ideal platform for social exchange because of the opportunity for new and continued business-customer relationships at a relatively low cost to businesses (Surma, 2016). We used adoption and social exchange theories as a basis for understating the social media adoption and exchange process for landscape industry small businesses included in this study. Adoption and 
social exchange theories helped us understand factors that resulted in a successful adoption process, factors that could hinder the adoption process, and the impact of the overall social exchange process within facets of social media marketing.

\section{Method}

A qualitative, exploratory multiple-case study design was used to explore how landscape industry small business owners use social media marketing strategies to help ensure business viability. A qualitative case study design was appropriate for obtaining an in-depth understanding of how and why landscape industry small business owners used social media marketing strategies. Incorporating data from a variety of sources strengthened the understanding of landscape industry small business owners' successful use of online marketing strategies. Using a multiple case study design ensured data saturation by providing more substantial data that allows for comprehensive analysis and pattern repetition (O'Reilly \& Parker, 2013; Yin, 2014). After obtaining IRB approval (approval \#11-03-17-0487630), data collection commenced and included both semi-structured interviews and content analysis of the social media sites of landscape industry small businesses included in this study.

Potential participants for this study were initially contacted through their social media sites on Facebook. This offered an advantage because it was important to understand the level of online two-way engagement of the participants since this was a social media marketing study. We gave participants consent forms and the interview questionnaire. Participants within the study were allowed to return the questionnaires to me in a manner of their choosing. Some of the responses were verbally captured, while others were emailed or captured in online message correspondence. We reviewed the responses and asked follow-up clarifying questions when necessary. An advantage of using this dual technique was that the participant was able to clarify their intended responses, thus improving reliability and validity. Once the interviews concluded, social media content analysis followed. Key data captured in the content analysis included the number and content of posts across various social media sites including Facebook, Twitter, Instagram, and company websites. The four cases used in this study were designated as Landscape Small Business (LBS) 1-4 in the results below.

\section{Results}

The purpose of this qualitative multiple case study was to explore how four small businesses within the landscape industry located in central Alabama have successfully incorporated social media marketing strategies to help ensure business viability. Several key findings emerged from our thematic data analysis. Key findings included social media usage as part of an overall marketing strategy, the use of Facebook as a primary type of social media, similarities across Facebook content, and the benefits and challenges of social media use.

\section{Marketing Strategy Adoption}

Each small business within the landscape industry used social media marketing, including Facebook, a company website, Twitter, and Instagram, as part of an overall marketing strategy; however, the extent varied. For example, LSB 3 used social media marketing for "more than half of all my marketing." Whereas, by contrast, LSB 1 primarily relied on word-of-mouth referrals with limited use of social media for those referrals, highlighting the importance of social media as "a placement aspect of marketing, in that hopefully more people in our area are aware of our service.”

Word-of-mouth referrals were an interesting finding because they encompassed both social media marketing through service reviews as well as traditional word-of-mouth marketing through friends and family. For example, LSB 4 stated, "I guess I just take pride in publicly posting my work and seeing who looks at them and 
likes them in hope that they would want to hire me in the future." This statement highlighted the importance of word-of-mouth marketing in that the owner was able to start a word-of-mouth referral through pictures, and when multiple people "liked" a picture he was able to promote his company's work. Participants' pride in their work was often a key element noted in the importance of providing customers with social media picture displays. Similarly, LSB 2 stated, "when customers see my work and like my posts, then other potential customers will sometimes call and say, 'I saw this rock bed you did on Facebook' and then want something similar." Overall, both followership and likability were important factors in word-of-mouth marketing as they related to social media marketing and the participants' abilities to expand their customer base.

\section{Facebook as a Key Social Media Tool}

The second theme revealed through data analysis regarded the primary types of social media used. All participants used Facebook as a primary social media marketing tool. Some also used social media tools such as Instagram, Twitter, and a company website, but this was less prevalent in their overall marketing strategy. An interesting finding was that although many of the companies had briefly used, either currently or in the past, other social media marketing tools, Facebook was the primary social media site used.

For example, LSB 1 discussed how Facebook, in his experience, was the best way to reach a potential customer base, noting "Facebook shows the reach of your posts and the insights on the statistics/demographics of who and how many people have seen your posts. Facebook insights will also tell you what days and what time of the day are best to reach the most people.” As LSB 3 discussed, "Facebook works best as I can get my customers to follow my page but I have not had as much luck with Twitter or Instagram." LSB 2 noted the ability for customers to directly message through the Facebook page: "I get a lot of customers who see work I did on someone's Facebook page, then they message me directly. It saves the customer time because they don't have to look up my phone number, they can just click a button rather than having to place a phone call."

Many participants noted that most of their customer base had a Facebook page of their own, unlike other social media tools such as Twitter or Instagram that tended to appeal to a more limited audience. Despite the noted lack of customer use of Twitter or Instagram, most participants reported that they did use other forms of social media such as Instagram, Twitter, or a personal company website to reach and expand their customer base.

Three of the small business owners interviewed indicated that they did have a personal company website at one point but that they were no longer active, noting a lack of two-way communication on a website as could be experienced through Facebook. Although some of the small businesses had used Twitter, one stated, "I have not had as much luck with Twitter," primarily due to a lack of followers. Interestingly, even though participants quite often used Facebook to post pictures of their services, none of the participants used Instagram despite it being a picture-based social media tool. Participants noted not having very many customers and/or followers who regularly used the site. Table 1 illustrates the main types of social media used in each case and how, despite trying out various types of social media, Facebook remained one of the most used tools across the cases included in this study. 
Table 1: Type of Social Media Used by Landscape Small Business Cases

\begin{tabular}{lcccc}
\hline Case & Twitter & Facebook & $\begin{array}{c}\text { Company } \\
\text { website }\end{array}$ & Instagram \\
\hline LSB 1 & yes $^{*}$ & yes & yes $^{* *}$ & yes* $^{*}$ \\
LSB 2 & no & yes & yes & no \\
LSB 3 & yes & yes & yes & no \\
LSB 4 & no & yes & no & no \\
\hline
\end{tabular}

Note. ${ }^{*}$ indicates site is not currently used; ${ }^{* *}$ site no longer active.

\section{Facebook Content}

Participants' Facebook content fell into three commonalities across all cases; these included services offered, educational postings, and holiday posts (Table 2). We measured these commonalities through a content analysis of the last six months of each participant's Facebook page.

\begin{tabular}{|c|c|c|c|}
\hline Case & Services & Educational & Holiday \\
\hline LSB 1 & $18(67 \%)$ & $3(11 \%)$ & $6(22 \%)$ \\
\hline LSB 2 & $11(79 \%)$ & $3(21 \%)$ & o (o\%) \\
\hline LSB 3 & $9(60 \%)$ & $3(20 \%)$ & $3(20 \%)$ \\
\hline LSB 4 & 12 (100\%) & o (o\%) & o (o\%) \\
\hline Total & $50(74 \%)$ & $9(13 \%)$ & $9(13 \%)$ \\
\hline
\end{tabular}

All four cases posted primarily about services offered. Services included general landscaping, irrigation, as well as flower and bed installation. Posts about services offered or performed made up $74 \%$ of all Facebook posts across all four cases. Within cases, LSB 1 posted about services $67 \%$ of the time, LSB 2 posted about services $79 \%$ of the time, LSB 3 posted about services $60 \%$ of the time, and LSB 4 posted about services $100 \%$ of the time. Educational posts made up about $13 \%$ of the total Facebook posts, across cases, during the sixmonths. Educational posts consist of articles, links, and general posts aimed to educate customers. LSB 1 and LSB 3 both discussed the challenge in finding educational content that was informative yet at a level that someone with little industry knowledge could understand. Holiday posts made up about $13 \%$ of the total postings across cases. Holiday posts included messages such as "Merry Christmas," "Happy Fourth of July," and other holiday-themed posts such as employee birthday and anniversary posts.

\section{Benefits and Challenges of Social Media Use}

The benefits and challenges of using social media as a marketing strategy were surprisingly similar across all four cases. The major benefits included social media as a low-cost marketing option and a strategy to improve visibility to increase customer base and improve customer retention. The major challenges included the trialand-error learning curve associated with social media marketing, as well as the ability, or inability, to direct customers to the businesses' social media sites. 
One of the greatest benefits discussed by all participants was the ability to use social media at a relatively low and, often, no cost. LSB 1 stated, "It is free! It has also increased our list of potential clients." LSB 3 noted, "The best thing about using social media is that it's free. That once my customers caught on they shared my information with their friends. It eventually spread via word-of-mouth which kept my advertising costs down." Each participant noted the low- or no-cost nature of social media. As researchers have noted, online social networks are an ideal platform for social exchange due to the opportunity for new and continued business-customer relationships at a relatively low cost to businesses (Araujo, et al., 2015; Hamilton, et al., 2016; Kohli, et al., 2015; Surma, 2016).

Small businesses have used social media marketing to promote themselves and increase visibility (Taneja \& Toombs, 2004). They found that the increase in self-promotion and visibility helped them survive in a competitive world (Taneja \& Toombs, 2004). The participants' comments in this study mirrored Taneja and Toombs's (2004) research findings regarding self-promotion and visibility. For example, LSB 1 noted that "pictures are important so people can see what I am capable of producing. Especially in my field, I can have a fancy webpage but that won't do me any good because people won't really know what I am capable of doing."

Researchers have indicated that as small businesses become immersed in social media marketing, they become a stronger market contender by acquiring market intelligence; yet, the adoption of social media best practices in small business continues to be deficient (Atanassova \& Clark, 2015; Shang, 2014). The question is why? This was answered through a major challenge noted by several of the participants, which was having to learn by trial and error to see what worked and what did not work in the world of social media marketing. LSB 4 discussed a major challenge in "figuring out how to successfully set up the pages myself and also how to generate likes and followers to get people to have interest in my page." LSB 2 noted that the "greatest challenge was having the time to come up with creative, intriguing posts to engage people to hopefully increase your reach.” LSB 1 employed a younger employee to run their social media sites stating:

I have delegated the social media aspect of the business to our 22-year-old employee, who is likely more knowledgeable about the in's and out's and tricks of the trade (like hashtags) of posting on social media. She seems to be able to do it much more quickly and more effectively than I did. She also has more time in her work week to do that.

\section{Discussion}

Social media has changed the way companies implement their marketing and customer relationship management practices (Dewan \& Ramaprasad, 2014; Felix, et al., 2016). Two-way communication channels within each social media tool largely impacted participants' adoption decisions. Participants' lack of two-way activity used on company websites, Twitter, and Instagram aligned with previous research noting the importance of two-way communication in social media adoption (Chang, et al., 2014; Csordas \& Gati, 2014).

Although social media marketing adoption provides several important advantages, certain factors hinder or slow the adoption process (Franklin, 2014; Pechrová, et al., 2015; Verheyden \& Goeman, 2013). The successful factor in this study was the adoption of a specific social media tool. Adoption decisions were based on a balancing act to mitigate between the best and most effective two-way communication tools available and extensively used by both customers and businesses. For example, Facebook was more effective than a company's website because customers were more likely to be on Facebook.

The low-cost nature of some social media sites, such as Facebook in particular, provided an opportunity for businesses to reach both new and existing customers as well as solicit two-way exchanges that are so valuable in terms of word-of-mouth marketing strategies (Charalabidis, et al., 2014; Chien-Wen, et al., 2014; Soyoung, et al., 2016). When service, education, and holiday social exchanges occurred through social media posts, 
Lupo \& Stroman, 2020

overall visibility of the participants' small businesses increased. Brand loyalty was reinforced through the visibility of services, as well as through educational posts. Companies also fostered a sense of community through the inclusion of holiday posts.

The challenges presented in this study supported Pechrová et al.'s (2015) research, which discussed a lack of understanding, familiarity with possibilities, and lack of experiences using social media as key obstacles to adoption. The business owners in this study were able to overcome these barriers to adoption. However, not all small business owners have the time or resources to mitigate the challenges to social media marketing adoption. So, while an effective business practice might be to adopt social media marketing, the obstacles might be insurmountable to small business owners who lack computer literacy or other resources to adequately create and maintain a social media presence. Despite the challenges presented and given the possibilities for increased visibility and effective word-of-mouth marketing at a low cost, small businesses should attempt to incorporate resources to enable the adoption of social media marketing, at least on some level.

The research problem presented in this study may be of significant interest to leaders who have the goal of positive social change. The SBA (2016) noted that small businesses have added roughly 8 million new jobs to the United States economy over the past 25 years; while by comparison, big businesses eliminated roughly 4 million jobs during that same period. Researchers have suggested that entrepreneurship and small business activity contributes to the larger society in terms of creating financial, environmental, and social wealth (Zahra \& Wright, 2015). While small businesses provide job opportunities to the United States economy, their continued failure rate has prevented the full realization of social change benefits. If small businesses can improve their long-term viability by incorporating social media marketing strategies, social change could potentially occur through an improved local economy and quality of life. Increased tax revenues due to viable small business ventures could contribute to positive social change through improvements in social institutions, such as public safety and schools.

State and community small business training efforts should focus on adoption of social media marketing strategies. Training could include local community classes on how to develop and effectively use social media sites to promote a small business, how to use social media on a smart device, as well as resources on how to find public computer availability at local colleges and libraries for those without in-home computers. Literature could be made publicly available at small business resource locations, such as the SBA, local libraries, labor boards, and community centers. Literature could describe the benefits and potential ways to incorporate social media into small businesses' overall marketing strategies. Training schedules could also be made publicly available at these venues.

\section{Future Research}

The participants in this multiple case study were limited to business owners with no more than 20 employees, within central Alabama, who had experience using social media marketing. Similar research could be performed within larger companies in the landscape industry as well as adapted to other industries. The study location could be expanded to a different state, region, or even across the United States to see if results vary. It might be interesting to see, for example, whether landscape industry small businesses in New York differ in their efficacious use of social media marketing, particularly if the post content subthemes of services, education, and holiday messages would be similar. Finally, broadening the study to the larger United States on specific uses of social media marketing, using a quantitative approach, might provide insight on social media usage on a much larger scale. 


\section{References}

Araujo, T., Neijens, P., \& Vliegenthart, R. (2015). What motivates consumers to re-tweet brand content? Journal of Advertising Research, 55, 284-295. doi.org/10.2501/JAR-2015-009

Atanassova, I., \& Clark, L. (2015). Social media practices in SME marketing activities: A theoretical framework and research agenda. Journal of Customer Behaviour, 14, 163-183. doi.org/10.1362/147539215X14373846805824

Broekemeir, G., Chau, N., \& Seshadri, S. (2015). Social media practices among small business-to-business enterprises. Small Business Institute Journal, 11(1), 37-48. http://www.sbij.org/index.php/SBIJ

Castronovo, C. \& Huang, L. (2012). Social media in an alternative marketing communication model. Journal of Marketing Development and Competitiveness, 6 (1), 117-131. http://www.nabusinesspress.com/jmdcopen.htm

Chang, Y., Yu, H., \& Lu, H. (2015). Persuasive messages, popularity cohesion, and message diffusion in social media marketing. Journal of Business Research, 68, 777-782. doi.org/10.1016/j.jbusres.2014.11.027

Charalabidis, Y., Loukis, E., \& Androutsopoulou, A. (2014). Fostering social innovation through multiple social media combinations. Information Systems Management, 31, 225-239. doi.org/10.1080/10580530.2014.923267

Chien-Wen, C., Wei-Cyuan, C., \& Wen-Kuo, C. (2014). Understanding the effects of eWOM on cosmetic consumer behavioral intention. International Journal of Electronic Commerce Studies, 5, 97-102. doi.org/10.7903/ijecs.1030

Csordás, T., \& Gáti, M. (2014). The new (marketing) role of firms as media content providers: The case of SME's strategic social media presence. Vezetéstudomány/Budapest Management Review, 45, 22-32. http://unipub.lib.uni-corvinus.hu/1447/

De Clercq, D., Dimov, D., \& Thongpapanl, N. (2010). The moderating impact of internal social exchange processes on the entrepreneurial orientation-performance relationship. Journal of Business Venturing, 25, 97-103. doi.org/10.1016/j.jbusvent.2009.01.004

Dewan, S., \& Ramaprasad, J. (2014). Social media, traditional media, and music sales. MIS Quarterly, 38, 101121. https://doi.org/10.25300/MISQ/2014/38.1.05

Felix, R., Rauschnabel, P.A., \& Hinsch, C. (2016). Elements of strategic social media marketing: A holistic framework. Journal of Business Research, 70, 118-126. doi.org/10.1016/j.jbusres.2016.05.001

Franklin, T. (2014). Mobile adoption on the rise among SMBs. Econtent, 37, 812. http://www.econtentmag.com/Articles/News/News-Feature/Mobile-Adoption-on-the-Rise-AmongSMBs-99674.htm

Gray, C. \& Mabey, C. (2005). Management development: Key differences between small and large businesses in Europe. International Small Business Journal: Researching Entrepreneurship, 23, 467-485. https://doi.org/10.1177/0266242605055908

Hamilton, M., Kaltcheva, V. D., \& Rohm, A. J. (2016). Social media and value creation: The role of interaction satisfaction and interaction immersion. Journal of Interactive Marketing (Mergent, Inc.), 36, 121133. doi.org/10.1016/j.intmar.2016.07.001

Homans, G. (1958). Social behavior as exchange. American Journal of Sociology, 63, 597-606. http://www.journals.uchicago.edu/toc/ajs/current

IBISWorld (2018). Landscape services industry in the U.S. https://www.ibisworld.com 
Kohli, C., Suri, R., \& Kapoor, A. (2015). Will social media kill branding? Business Horizons, 58, 35-44. doi.org/10.1016/j.bushor.2014.08.004

Lawn \& Landscape (2018). State of the industry report. https://giecdn.blob.core.windows.net/fileuploads/document/2018/11/06/2018\%20soi.pdf

Lupo, C. (2015). Adoption of innovation in small-scale forestry: The case of portable-sawmill-based microenterprises. Journal of Social Change, 7, 28-38. doi.org/10.5590/JOSC.2015.07.1.03

Lupo, C. (2018). Social media marketing strategies in landscape industry small businesses. [Doctoral dissertation, Walden University]. ProQuest Dissertations and Theses Global.

O’Reilly, M., \& Parker, N. (2013). "Unsatisfactory saturation": A critical exploration of the notion of saturated sample sizes in qualitative research. Qualitative Research, 13, 190-197. doi.org/10.1177/1468794112446106

Pechrová, M., Lohr, V., \& Havlíček, Z. (2015). Social media for organic products promotion. Agris On-Line Papers on Economics \& Informatics, 7, 41-50.

Perry, M. (2014). Market orientation in small businesses: Creative or lacking? Marketing Management Journal, 24, 96-107.

Ramirez, E. (2013). The consumer adoption of sustainability-oriented offerings: Toward a middle-range theory. Journal of Marketing Theory \& Practice, 21, 415-428. doi.org/10.2753/MTP1069$\underline{6679210405}$

Rogers, E. (2003). Diffusion of innovations (5th ed.). The Free Press.

SBA (2016). Small business trends. https://www.sba.gov/managing-business/running-business/energyefficiency/sustainable-business-practices/small-business-trends

Setiowati, R., Hartoyo, H, Daryanto, H. K., \& Arifin, B. (2015). The effects of ICT adoption on marketing capabilities and business performance of Indonesian SMEs in the fashion industry. Journal of Business \& Retail Management Research, 10, 100-115. doi.org/10.24052/JBRMR/206

Shang, Y. (2014). Adoption of social media by SMTEs in China. University of Exeter. http://hdl.handle.net/10871/15578

Soyoung, K., Martinez, B., McClure, C., \& Soo Hyun, K. (2016). eWOM intentions toward social media messages. Atlantic Marketing Journal, 5, 137-154. http://digitalcommons.kennesaw.edu/amj/

Stone, G. (2016). Toward a general theory of agricultural knowledge production: Environmental, social, and didactic learning. The Journal of Culture and Agriculture, 38, 5-17.

https://doi.org/10.1111/cuag.12061

Surma, J. (2016). Social exchange in online social networks. The reciprocity phenomenon on Facebook. Computer Communications, 73, 342-346. doi.org/10.1016/j.comcom.2015.06.017

Taneja, S., \& Toombs, L. (2014). Putting a face on small businesses: Visibility, viability, and sustainability the impact of social media on small business marketing. Academy of Marketing Studies Journal, 18, 249-260. https://www.researchgate.net/publication/286103279

Taylor, D. G., Voelker, T. A., \& Pentina, I. (2011). Mobile application adoption by young adults: A social network perspective. International Journal of Mobile Marketing, 6, 60-70.

Verheyden, M., \& Goeman, K. (2013). Does (company) size matter?: Differences in social media usage for business purposes. Journal of Applied Quantitative Methods, 8, 3-16. http://www.jaqm.ro/issues/volume-8,issue-4/pdfs/1_VERHEYDEN GOEMAN.pdf

Yin, R. K. (2014). Case study research: Design and methods (5th ed.). Sage. 
Lupo \& Stroman, 2020

Zahra, S. \& Wright, M. (2015). Understanding the social role of entrepreneurship. Journal of Management Studies, 53, 610-629. doi.org/10.1111/joms.12149

$\mathbb{4} \mid \mathrm{JSBHS}$

The Journal of Social, Behavioral, and Health Sciences (JSBHS), co-sponsored by the College of Health Sciences and the College of Social and Behavioral Sciences at Walden University, is a peer-reviewed, online, interdisciplinary journal focusing on theoretically-based research that addresses contemporary national and international issues. JSBHS articles include peer-reviewed research reports, brief reports, comprehensive literature reviews, books reviews, and student research. 